\title{
Different responses of running wheel and Animex activity to restricted feeding and drug-induced anorexia in rats
}

\author{
KATSUYA NAGAI, TSUTOMU MORI and HACHIRO NAKAGAWA \\ Division of Protein Metabolism, Institute for Protein Research, Osaka University, Yamada-oka, Suita, \\ Osaka 565, Japan
}

\begin{abstract}
The motor activity measured by a running wheel (running wheel activity) and an Animex meter (Animex activity) was compared in two groups of rats under a 3hour meal feeding schedule (1400-1700) and in anorexia induced by injection of mazindol, an anorectic drug. It was found that the responses of the two types of activity to food intake were completely different; during the meal feeding period with the food intake reduced, the running wheel activity increased, whereas the Animex activity decreased. A single injection of mazindol $(30 \mathrm{mg} / \mathrm{kg})$, which resulted in hypophagia, caused an increase in the running wheel activity, but it did not induce a significant increase in the Animex activity. From these findings, we suggest that the two types of activity might be differently motivated.
\end{abstract}

It is generally accepted that changes in nutritional condition are associated with changes in spontaneous motor activity. For example, the activity of rats decreases in obesity induced by ventromedial hypothalamic lesion $(3,5,8,9,13)$, and increases during total food deprivation, food restriction, meal feeding or nutritional deficiency $(1,4,9,11,13,14)$. However, even in the same nutritional condition different measures for the activity do not necessarily give consistent results. For example, it has been reported that the activity measured by a running wheel was permanently reduced in obese rats with ventromedial hypothalamic lesion, but the activity measured by a tambour first decreased, then increased, and finally exceeded the preoperative level (3). It was also reported that in rats made obese by treatments with monosodium glutamate the activity measured by an Animex meter decreased (12), but activity measured by a Whahmann activity wheel increased (10). In this paper we report that when rats were transferred from free feeding to meal feeding or to drug-induced anorexia, the activity measured by the running wheel method (running wheel activity) and the activity measured by an Animex activity meter (Animex activity) do not change either in the same direction or in the reverse direction.

Male Wistar strain rats, weighing $120-140 \mathrm{~g}$ initially, were used. One group of rats were housed individually in metallic cages $(13.5 \times 40 \times$ 18 (height) $\mathrm{cm}$ ), each with a running wheel $1 \mathrm{~m}$ in outer diameter (running wheel group), and the other groups were in plastic cages $(33 \times 36 \times 18$ (height) $\mathrm{cm}$ ), each placed on an MK-Animex activity meter (Muromachi Kikai Co., Tokyo) (Animex group). The sensitivity of the Animex meter was set at $35 \mu \mathrm{A}$. The animals were given laboratory chow pellets, MF (Oriental Yeast Co., Osaka), and had free access to water. The daily food intake and the activity meters were checked at 1700 every day. The animal room was maintained at $24 \pm 1{ }^{\circ} \mathrm{C}$ and $60 \%$ relative humidity, and illuminated for $12 \mathrm{~h}$ from 0800 . Rats were made anorectic by using mazindol $(2,6,7)$ (Sandoz Pharmaceuticals, Basel) dissolved in 0.01 $\mathrm{N} \mathrm{HCl}$. It was injected subcutaneously in a dose of $30 \mathrm{mg} / \mathrm{kg}$.

First, the animals were allowed to eat freely for 17 days (first free feeding period). On the 17th day they were starved from 1700 onward. On the next day the meal feeding schedule was initiated in which each day the animals were fed only from 1400 to 1700 . This was continued for 
three weeks (meal feeding period). On the last day of meal feeding the animals were presented with food from 1700 onward. The next day was the first day of the second free feeding period which lasted for 14 days. After passing through the second free feeding period, the animals were subjected to the second experiment in which the effects of mazindol were examined. After control observation of food intake and activity for 2 days the animals were injected with $0.02 \mathrm{ml}$ of $0.01 \mathrm{~N} \mathrm{HCl}$ subcutaneously on the third day and with the mazindol solution on the 4th day. Observations were continued till the 6th day. Throughout this experiment the animals were maintained on the free feeding schedule.

Three rats belonged to the running wheel group and another three to the Animex group. Means of daily food intake (g) and amount of activity expressed as the percentage of the two groups are shown in Fig. 1 as functions of the experimental day. During the first free feeding period there was a tendency for the running wheel group to eat less than the Animex group. In the meal feeding period both groups showed a marked decrease of food intake, with the difference between the two groups greatly reduced. Although both groups gradually increased food intake as time passed, the level finally attained was lower than that at the end of the first free feeding period. Initiation of the second free feeding schedule resulted in an increase of food intake to a level much higher than at the end of the meal feeding period. This was the same for the two groups. Again it was found that the running wheel group ate less than the Animex group under the free feeding schedule. Although it was thus established that the meal feeding schedule affected the food intake in the same way in the two groups, such was not true with the activity measure. As soon as the meal feeding schedule was started, the running wheel activity began to increase and within three days it reached
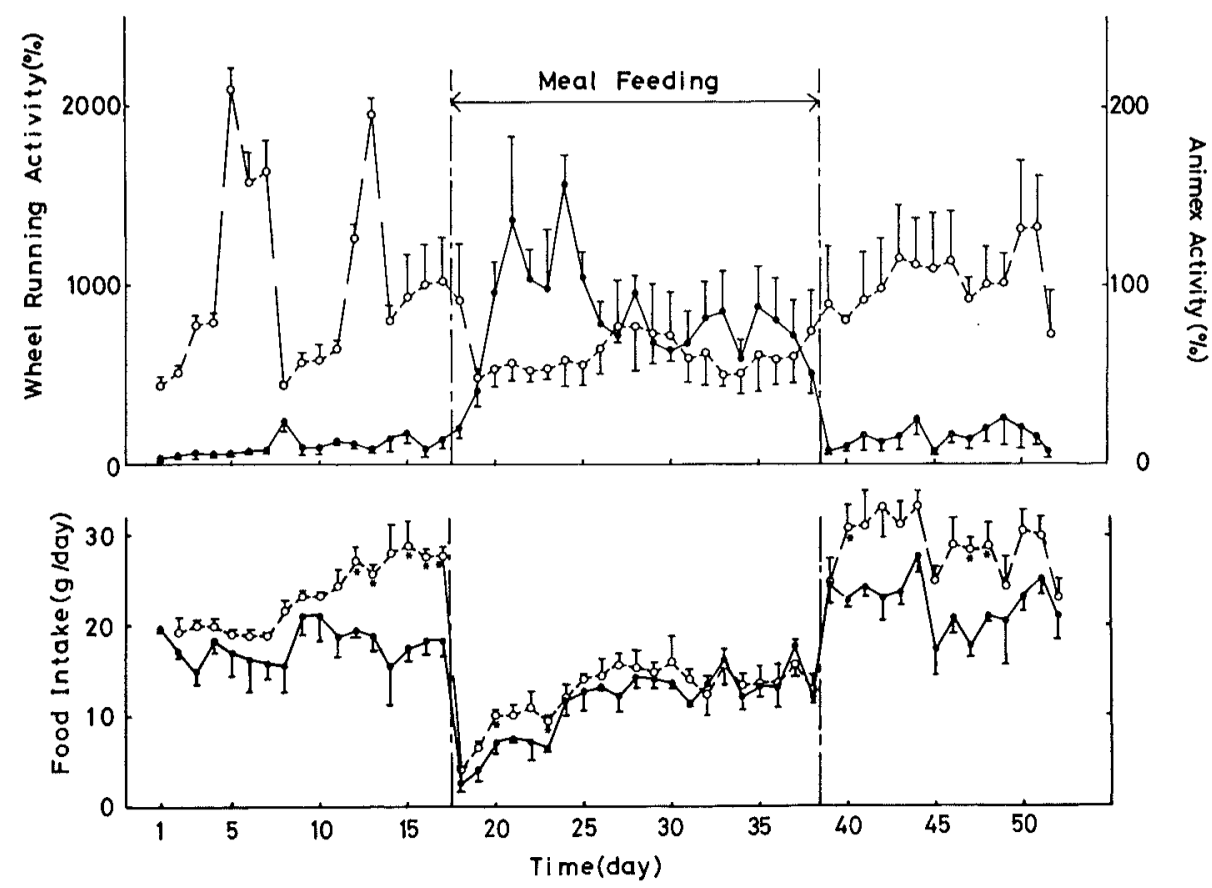

Fig. 1 Effects of meal feeding on food intake and motor activity. Rats were divided into two groups of three. The data of motor activity are expressed as percentage. The mean running wheel activity of each rat during the first free feeding period was 559,713 , and 558 rotations per day, respectively. The mean Animex activity of each rat during the first free feeding period was $71,841,34,957$, and 55,256 counts per day, respectively. The means were indicated as $100 \%$ for each rat. Each plot represents means $\pm \mathrm{SEM}$. * a significant difference in food intake between the two groups of rats $(P<0.05$ by Student's $t$-test $)$ 
level about 5 times higher during the first free feeding period, and thereafter it remained above that level until the end of the meal feeding period. In contrast to this, the Animex activity was definitely reduced by the meal feeding schedule and remained lower than during the first free feeding period. After the second free feeding schedule was started, the running wheel activity decreased and the Animex activity increased; the levels of the two activity measures during the second free feeding period were about the same as their respective controls during the first one. The Mann-Whitney $U$ test showed significant differences between the running wheel activity during the first free feeding period and that during the meal feeding period $(P<0.001)$ and between the activity during the meal feeding peirod and that during the second free feeding period $(P<0.001)$. The Mann-Whitney $\mathrm{U}$ test also showed significant differences between the Animex activity during the first free feeding period and that during the meal feeding period $(P<$ 0.001 ) and between the activity during the meal feeding period and that during the second free feeding period $(P<0.001)$.

The results of the second experiment are shown in Fig. 2. In the two groups with different activ- ity measures, injection of the solvent $(0.01 \mathrm{~N}$ $\mathrm{HCl}$ ) did not affect either food intake or activity. After injection of mazindol the food intake in the two groups transiently decreased, and the decrease lasted slightly longer in the running wheel group than in the Animex group. The activity measures responded to mazindol in the following way: whereas the running activity increased to 5 times the control and remained high thereafter, the Animex activity remained at about the same level as before injection, though there was an increase of insignificant magnitude on the day after the injection. From these findings it seems likely that the mazindol-induced anorexia causes an increase in the running wheel activity but not in the Animex activity.

The present observation that the running wheel activity increases in transition from free feeding to meal feeding is consistent with previous observations that this measure increases in rats deprived of food or subjected to restriction of food (11). On the other hand, an Animex meter measures all kinds of movements such as grooming, ambulatory movements, etc. That this measure decreases or does not increase in the food-restricted or anorectic state seems to imply that the rats are attempting to save redundant
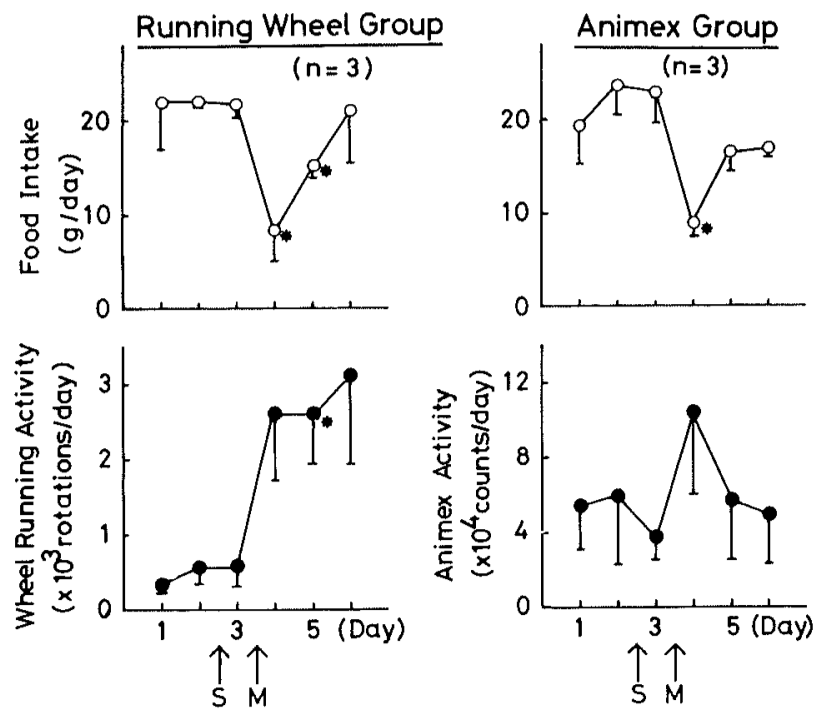

Fig. 2 Effect of subcutaneous injection of mazindol on food intake and activity. Injections of mazindol (M) and its solvent (S) were carried out at around 1700 on day 4 and 3, respectively. Data from the running wheel group are at the left and those from the Animex group at the right. Statistical analysis (Student's ttest) was made of food intake and the two types of activity between those on day 3 and on day 4,5 , or 6 . * a significant difference $(P<0.05)$ 
movements because of the lowering of the basal metabolism. This characteristic of the Animex activity is revealed only in rats confined to cages without running wheels. Thus it is apparent that a running wheel measures different aspects of the motor activity from those measured by an Animex meter.

We thank Professor K. Iwama for his help in preparing the manuscript. This work was supported by the Ministry of Education, Science and Culture, Japan with a grant-in-aid for Special Project Research, 'Mechanism of Animal Behavior,' and by a grant-inaid from the Naito Science Foundation and Sandoz Pharmaceuticals, Ltd.

Received for publication 8 March 1982; and in revised form 14 April 1982

\section{REFERENCES}

1. Armstrong S., Coleman G. and Singer G. (1980) Food and water deprivation: Changes in rat feeding, drinking activity and body weight. Neurosci. Biobehav. Rev. 4, 377-402

2. Bradley M. N., Blum N. Y. and Schiel R. T. (1974) Mazindol in obesity with known cardiac disease: A clinical evaluation. J. Int. Med. Sci. 2, 347-349

3. Brooks C. McC. (1946) The relative importance of changes in activity in the development of experimentally produced obesity in the rat. Amer. J. Physiol. 147, 708-716

4. Gladfelter W. E. (1978) Locomotor response to changes in food intake and ambient temperature in rats with hypothalamic lesions. Physiol. Behav. 20, 227-231

5. Gladfelter W. E. and Brobeck J. R. (1962)
Decreased spontaneous locomotor activity in the rat induced by hypothalamic lesions. Amer. $J$. Physiol. 203, 811-817

6. Goldrick R. B., Nestel P. J. and Havenstein N. (1974) Comparison of a new anorectic agent AN 448 with fenfluramine in the treatment of refractory obesity. Med.J. Australia 1, 882-885

7. Hadler A. J. (1972) Mazindol, a non-amphetamine anorexigenic agent. J. Clin. Pharmacol. 12, 453-458

8. Hetherington A. W. and Ranson S. W. (1942) The spontaneous activity and food intake of rats with hypothalamic lesions. Amer. J. Physiol. $136,609-617$

9. Kennedy G. C. and Mitra J. (1963) Hypothalamic control of energy balance and the reproductive cycle in the rat. J. Physiol. 166, 395-407

10. Nikoletseas M. M. (1977) Obesity in exercising, hypophagic rats treated with monosodium glutamate. Physiol. Behav. 19, 767-773

11. REID L. S. and Finger F. W. (1955) The rats' adjustment to 23-hour food-deprivation cycles. J. Comp. Physiol. Psychol. 48, 110-113

12. Takasaki Y., Matsuzawa S., Iwata Y., O'Hara S., Yonetani S. and Ichimura M. (1979) Toxicological studies on monosodium L-glutamate in rodents: Relationship between routs of administration and neurotoxicity. In Glutamic Acid: Advances in Biochemistry and Physiology (ed. Filer L. J., Garattini S., Kare M. R., ReYNolds W. A. and Wurtman R. J.) Raven Press, New York, pp. 255-275

13. Teitelbaum P. (1957) Random and food-directed activity in hyperphagic and normal rats. $J$. Comp. Physiol. Psychol. 50, 486-490

14. WALD G. and JACKSON B. (1944) Activity and nutritional deprivation. Proc. Natl. Acad. Sci. USA 30, 255-263 